\title{
Relaxation incisions of venomous snake "Japanese mamushi" bites to the hand
}

This article was published in the following Dove Press journal:

International Medical Case Reports Journal

I3 December 201 I

Number of times this article has been viewed

\section{Akira Sugamata \\ Naoki Yoshizawa \\ Takahiro Okada \\ Department of Plastic and Reconstructive Surgery, Tokyo Medical University Hachioji Medical Center, Tokyo, Japan}

\begin{abstract}
Gloydius blomhoffii, commonly known as Japanese mamushi, is a venomous viper species found widely in Japan. The most frequently bitten regions are the fingers and toes, and severe swelling causes compression of peripheral arteries and/or compartment syndrome of the extremities. We experienced four cases of mamushi bites to the hand, and undertook relaxation incision in the hands of three of these patients. As a result, the patients who underwent relaxation incision did not show any skin necrosis or permanent sensory disturbance in the affected fingers. Relaxation incision can be useful to not only decompress subcutaneous and compartment pressure of the hand, but also to wash out the venom from the bitten region by improving venous and lymphatic drainage.
\end{abstract}

Keywords: mamushi, snakebite, viper, relaxation incision

\section{Introduction}

In Japan, 2000-3000 people are bitten by mamushi every year and approximately ten victims die. Although fatality rates of mamushi bites are generally low, severe cases can be lethal with cardiac, pulmonary, and/or renal dysfunction caused by the snake's venom. In addition, focal skin necrosis, muscle degeneration, peripheral neuropathy, disseminated intravascular coagulation (DIC), and hemolysis have also been reported.

The most frequently bitten regions are the fingers and toes, and severe swelling causes compression of peripheral arteries and/or compartment syndrome of the extremities. When ischemic tissue damage or compartment syndrome in the hand is strongly suspected from clinical observation, relaxation incision should be performed as soon as possible to prevent muscle and nerve damage. We undertook relaxation incision in the hands of three patients out of four cases of mamushi bites to the hand. Here, we propose this as a standard remedy for mamushi bites to the hand.

\section{Patients Case I}

A 46-year-old man was bitten by a mamushi in the proximal ulnal side of his right index finger while he was mowing in his garden. He was given antivenom (6000 units) together with hydrocortisone sodium succinate $(100 \mathrm{mg})$ intravenously. He was also given Cepharanthin (10 mg) for 5 days from the first day of injury. On the second day after injury, his white blood cell (WBC) value rose to $16,200 / \mu \mathrm{L}$. The number of WBCs decreased day-by-day following a dose of systemic antibiotics.
Correspondence: Akira Sugamata Department of Plastic and Reconstructive Surgery, Tokyo Medical University Hachioji Medical Center, II63 Tatemachi, Hachioji City, Tokyo 193-0998, Japan

$\mathrm{Tel}+8 \mathrm{I} 4266556 \mathrm{II}$

Fax +8I 42665 I796

Email sugamata@tokyo-med.ac.jp 
At first examination, this patient's injured hand was markedly swollen and red; he complained of severe pain and numbness of the finger. Relaxation incision was not carried out due to the judgment of the doctor in charge. On the second day, swelling extended to the upper extremities, and a blister appeared in the bitten region of his index. On the fourth day, the skin color under the blister was dark. The dark skin area had become completely necrotic by the tenth day following the injury. On the 29th day after injury, debridement and a split-thickness skin graft from the right thenar region were carried out, with the grafted skin having completely taken 1 week after the operation. Five years after the operation, there is no contracture in the right index, however the patient still complains of sensory disturbance in the tip of his right index (Figure 1).

\section{Case 2}

A 20-year-old man was bitten by a mamushi on the proximal dorsum of the left index while he was examining wild plants in the mountains. He was given antivenom (6000 units) together with hydrocortisone sodium succinate $(200 \mathrm{mg})$. He was dosed with Cepharanthin $(10 \mathrm{mg}$ ) for 3 days from the day of admission. His laboratory data was within normal limits on the second day, with the exception of WBC (8000/ $\mu \mathrm{L}$ ), and he had no organ dysfunctions.

On the first day of injury, the patient complained of severe pain, numbness of the index finger, and swelling in the affected left hand. Relaxation incision was performed on both sides of the index finger 3 hours after injury; however, the severe pain and numbness of the finger did not decrease. Therefore, relaxation incisions in the dorsal hand, the lateral thenar, and the distal portion of the flexor retinaculum were added. All hand symptoms decreased from the second day after surgery. The incision wounds were sutured on the 11th day after injury, and the patient has not experienced any permanent complications in his left hand (Figure 2).

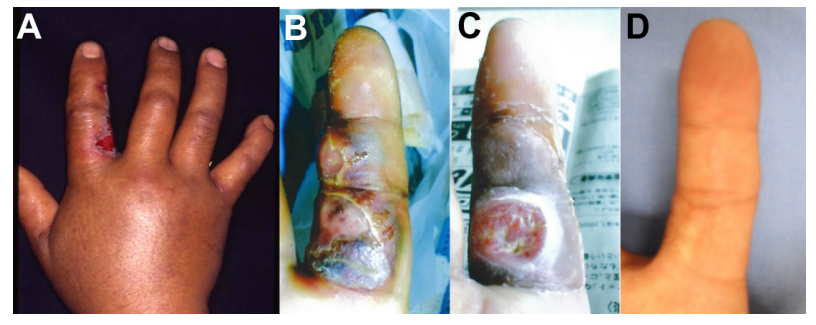

Figure I A 46-year-old man, 2 days after snakebite injury (A), 10 days after injury (B), 4 weeks after injury, the bitten skin had become necrotic (C). Five years after the skin graft, the grafted skin has a very good appearance; however, permanent sensory disturbance in the tip of the index finger exists (D).

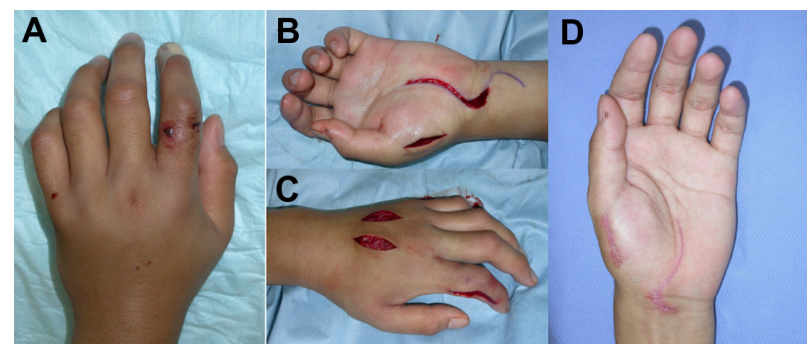

Figure 2 A 20-year-old man with a bite to the proximal dorsum of the left index (A). Relaxation incision was performed on both sides of the index, the dorsal hand and the distal portion of the flexor retinaculum (B and $\mathbf{C}$ ). Three months after injury, he had no sequelae in his hand (D).

\section{Case 3}

An 11-year-old boy was bitten by a mamushi in the proximal crease of the left index finger on his way from school. He was given antivenom (6000 units) together with hydrocortisone sodium succinate $(100 \mathrm{mg})$. Cepharanthin $(10 \mathrm{mg})$ was administered to him for the first 5 days from the original injury. His WBC value rose to $10,800 / \mu \mathrm{L}$ on the first day, however it decreased gradually from the second day after injury. He had no organ failure while hospitalized.

At the first examination, the patient complained of severe pain in his left index and his hand showed severe swelling. Three hours after the injury, the first relaxation incision was performed on the lateral side of the index. However the numbness of the index finger continued, and the subcutaneous tissue pressure of the dorsal hand was $70 \mathrm{mmHg}$. Therefore, relaxation incision to the dorsum of the hand and lateral thenar were added. After this treatment, the subcutaneous tissue pressure decreased to $18 \mathrm{mmHg}$, and numbness of the index finger decreased. Seven days after injury, the incision wounds were all sutured. There have been no complications in his left hand (Figure 3).

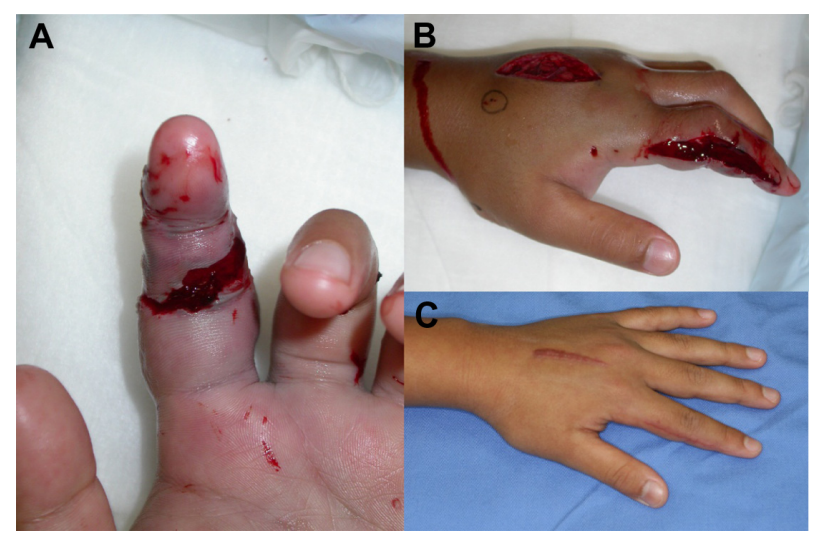

Figure 3 An II-year-old boy was bitten by a mamushi on his left index finger (A). Relaxation incision was performed in the lateral side of the index, the dorsum of the hand, and the lateral thenar (B). He had no complaints 4 months after injury (C). 


\section{Case 4}

An 8-year-old boy was bitten by a mamushi on the dorsum of his left thumb when he grasped a snake on the way home from school. He was given 6000 units of antivenom with methylprednisolone sodium succinate ( $40 \mathrm{mg}$ ). Cepharanthin $(10 \mathrm{mg})$ was also administered intravenously for 3 days. The number of WBCs rose to $12,300 / \mu \mathrm{L}$, and the creatine kinase value was $248 \mathrm{IU} / \mathrm{L}$ on the second day after injury, but both of these decreased gradually after that time. He did not suffer any serious organ failure.

At the initial examination, his left hand had notable redness and swelling, and he also complained of pain and numbness of the left thumb. Three hours after the injury, the first relaxation incision was performed in the lateral side of the thumb. However, the numbness of the thumb continued, so relaxation incision in the dorsal hand, the lateral thenar, and partial incision to the flexor retinaculum were added. Following this, both the numbness of the finger and swelling of the hand diminished. The incision wounds of the relaxation incisions were all sutured 10 days after injury following an improvement in swelling. There were no complications experienced in his hand (Figure 4).

\section{Discussion}

Gloydius blomhoffii, commonly known as mamushi, is a pit viper found in Japan, Korea, and China. ${ }^{1,2}$ The venom of mamushi is composed of several enzymatic components such as phospholipases and proteinases. ${ }^{3}$ These cause local tissue necrosis at the bite site, alter blood vessel permeability, and destroy red blood cells. As a result of hemorrhagic, degenerative, and coagulation-necrotic changes in the parenchymal organs, the venom leads to hypovolemic shock, renal failure, cardiovascular disorders, and disseminated intravascular coagulopathy (DIC). ${ }^{4}$ Such systemic abnormities often result in death.

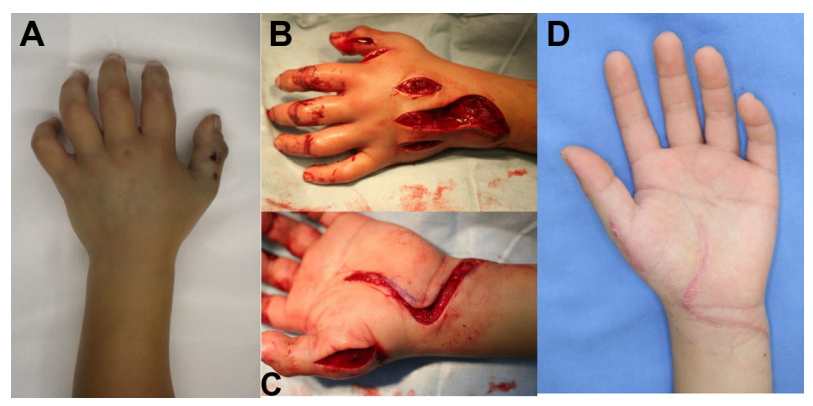

Figure 4 An 8-year-old boy was bitten by a Japanese mamushi on the dorsum of his left thumb (A). Relaxation incision was performed in the lateral side of the thumb, the dorsal hand, and the flexor retinaculum (B and $\mathbf{C})$. He had no complaints 5 months after the snakebite (D).
Therapy for mamushi bites is generally composed of doses of antivenom, corticosteroid, and cepharanthin. ${ }^{5}$ Antivenom therapy is intended to neutralize and eliminate the toxic potential of venom. ${ }^{6,7}$ Antivenom can minimize morbidity and mortality when administered early in the treatment of venomous snakebites. ${ }^{8}$ On the other hand, several authors have suggested that antivenom is unnecessary for patients with mild envenomation. ${ }^{9,10}$ Their view is based on the grounds that antivenom is potentially hazardous due to allergic reactions. We used 6000 units of freeze-dried equine antivenom uniformly with corticosteroids, because steroids are said to relieve systemic toxic effects of antivenom and to prevent allergic reactions to antivenom. ${ }^{8}$ We did not experience any serious allergic complications in this series. Cepharanthin is one of the biscoclaurine-type alkaloids extracted from the root of Stephania cepharantha, and has been documented as effective for Japanese viper bites by stabilizing the cell membrane and inhibiting phospholipase A2 activity, which is known as a hemolytic poison. ${ }^{3}$ In this series, all patients were administered Cepharanthin $(10 \mathrm{mg})$ intravenously for several days. None of the patients reported here showed any organ failure during hospitalization following this combination of therapies.

The regions most frequently bitten by mamushi are the fingers and toes. The injected venom causes severe pain, numbness, swelling, and hemolysis in bitten extremities. Severe swelling causes compression of peripheral arteries and/or compartment syndrome of the extremities, which often leads to focal skin necrosis and muscle and/or nerve degeneration. ${ }^{11,12}$

When ischemic tissue damage or compartment syndrome of the hand is strongly suspected from clinical observation or high compartment pressure $(>30 \mathrm{mmHg})$, relaxation incision should be performed immediately to prevent permanent damage to the muscles and nerves. ${ }^{11-13}$ High pressures in subcutaneous tissue $(>25-30 \mathrm{mmHg}$ ) can be useful information when it is impossible to calculate compartment pressure. Recently, several noninvasive techniques such as ultrasound and measurement of tissue hardness were reported to be useful in evaluating high compartment pressure. ${ }^{14,15}$ Though these techniques may be useful for diagnosis of compartment syndrome, they are not yet generalized clinically. Under conditions where it is difficult to measure compartment pressure, classical signs and symptoms are the most reliable indication for surgery. ${ }^{12,13}$ Once the decision had been made to perform relaxation incision in response to clinical symptoms, the first incision was made in the lateral side of the bitten finger to improve arterial blood supply to the affected finger. If the 
Table I Patient characteristics

\begin{tabular}{llllll}
\hline $\begin{array}{l}\text { Case } \\
\text { number }\end{array}$ & $\begin{array}{l}\text { Age, } \\
\text { years }\end{array}$ & Bitten region & $\begin{array}{l}\text { Relaxation } \\
\text { incision }\end{array}$ & $\begin{array}{l}\text { Time to } \\
\text { incision }\end{array}$ & Region of incision \\
\hline I & 46 & Right index finger & - & - & - \\
2 & 20 & Left index finger & + & 3 hours & $\begin{array}{l}\text { Finger, dorsal hand, lateral thenar, } \\
\text { flexor retinaculum }\end{array}$ \\
3 & II & $\begin{array}{l}\text { Left index finger } \\
\text { Left thumb }\end{array}$ & + & 3 hours & Finger, dorsal hand, lateral thenar \\
4 & 8 & & 3 hours & Finger, dorsal hand, lateral thenar, \\
\end{tabular}

symptoms continued after the first incision, skin incisions in the dorsum and lateral thenar of the hand were added with or without partial incision of the ligament of the flexor retinaculum (Table 1).

Relaxation incision can be useful not only to decompress subcutaneous and compartment pressure but also to wash out venom from the region of the bite by improving venous and lymph drainage. ${ }^{11}$ We think that washing out venom is very effective for avoiding skin and nerve damage. In the first case we did not carry out relaxation incision, and the patient complained of numbness of the index and showed severe swelling of the hand, which might have caused skin necrosis in the bitten region and permanent sensory disturbance of the index finger. In the other three cases, we undertook relaxation incision due to clinical symptoms such as numbness, pale skin color of the fingers, or increasing swelling of the hands in the early stages. The timing of relaxation incisions was about 3 hours from the initial bites. As a result, the patients did not show any skin necrosis or permanent sensory disturbance in the affected fingers. The disadvantages of relaxation incision are risks of bleeding and infection as well as the resulting incision scars. We undertook the surgical procedures under tourniquet and ensured hemostasis with an electric coagulator. As a result, there were no problems with bleeding after relaxation incision. We also had no trouble with infections due to the prophylactic use of a broad-spectrum antimicrobial agent. To diminish the width of the scars, we sutured the wounds after the swelling had decreased. There were slight scars in the dorsum of the hands of several patients; however, none of the patients were concerned by this outcome.

\section{Conclusion}

In three patients with mamushi bite injuries, relaxation incisions were performed according to the appearance of symptoms of pallor and numbness of the finger. As a result, they did not show any skin necrosis or permanent sensory disturbance in the affected fingers. Relaxation incision can be useful not only to decompress subcutaneous and compartment pressure of the hand but also to wash out the venom from the bitten region by improving venous and lymph drainage.

\section{Disclosure}

The authors report no conflicts of interest in this article.

\section{References}

1. Fukuda T, Iwaki M, Hong SH, et al. Standardization of regional reference for mamushi (Gloydius blomhoffi) antivenom in Japan, Korea, and China. Jpn J Infect Dis. 2006;59(1):20-24.

2. Yasunaga H, Horiguchi H, Kuwabara K, Hashimoto H, Matsuda S. Short report: Venomous snake bites in Japan. Am J Trop Med Hyg. 2011;84(1):135-136.

3. Kimoto T, Suemitu K, Nakayama H, Komori E, Ohtani M, Ando S. Therapeutic experience of venomous snakebites by the Japanese viper (Agkistrodon halys blomhoffii) with low dose of antivenin: report of 43 consecutive cases. Nihon Geka Hokan. 1997;66(2):71-77.

4. Okamoto O, Oishi M, Hatano Y, et al. Severity factors of Mamushi (Agkistrodon bomhoffii) bite. J Dermatol. 2009;36(5):277-283.

5. Hifumi T, Yamamoto Y, Morokuma K, et al. Surveillance of clinical use of mamushi (Gloydius blomhoffii) antivenom in tertiary care centers in Japan. Jpn J Infect Dis. 2011;64(5):373-376.

6. Walker JP, Morrison RL. Current management of copperhead snakebite. J Am Coll Surg. 2011;212(4):470-474.

7. Gold BS, Dart RC, Barish RA. Bites of venomous snakes. $N$ Eng J Med. 2002;347(5):347-356.

8. Russell FE, Carlson RW, Wainschel J, Osborne AH. Snake venom poisoning in the United States. Experience with 550 cases. JAMA. 1975;233(4):341-344.

9. White RR 4th, Weber RA. Poisonous snakebite in central Texas. Possible indicators for antivenin treatment. Ann Surg. 1991;213(5):466-471.

10. Whitley RE. Conservative treatment of copperhead snakebites without antivenin. $J$ Trauma. 1996;41(2):219-221.

11. Nemoto M, Aoyagi K, Sugimoto T, Nagashima K, Nakano K. Compartment syndrome caused by snake bite injury. J Jpn Soc Surg Hand. 2006;23:154-157. Japanese.

12. Evers LH, Bartscher T, Lange T, Mailänder P. Adder bite: an uncommon cause of compartment syndrome in northern hemisphere. Scand J Trauma Resusc Emerg Med. 2010;18:50.

13. Chandraprakasam T. Kumar RA. Acute compartment syndrome of forearm and hand. Ind J Plast Surg. 2011;44(2):212-216.

14. Garabekyan T, Murphey GC, Macias BR, Lynch JE, Hargens AR. New non-invasive ultrasound technique for monitoring perfusion pressure in a porcine model of acute compartment syndrome. J Orthop Trauma. 2009;23(3):186-194.

15. Joseph B, Varghese RA, Mulpuri K, Paravatty S, Kamath S, Nagaraja N. Measurement of tissue hardness: can this be a method of diagnosing compartment syndrome noninvasively in children? J Pediatri Orthop B. 2006; 15(6):443-448 
International Medical Case Reports Journal

Dovepress

\section{Publish your work in this journal}

The International Medical Case Reports Journal is an international, peer-reviewed open-access journal publishing original case reports from all medical specialties. Previously unpublished medical posters are also accepted relating to any area of clinical or preclinical science. Submissions should not normally exceed 2,000 words or

4 published pages including figures, diagrams and references. The manuscript management system is completely online and includes a very quick and fair peer-review system, which is all easy to use. Visit $\mathrm{http}: / / \mathrm{www}$.dovepress.com/testimonials.php to read real quotes from published authors.

Submit your manuscript here: http://www.dovepress.com/international-medical-case-reports-journal-journal 